\title{
Repeat procedures for recurrent colorectal liver metastases: analysis of long-term liver regeneration and outcome
}

This article was published in the following Dove Press journal: Cancer Management and Research

\author{
Valentinus T Valdimarsson ${ }^{\prime}$ \\ Katarina Hellberg ${ }^{2}$ \\ Torkel B Brismar ${ }^{3}$ \\ Ernesto Sparrelid ${ }^{2}$ \\ Christian Sturesson ${ }^{1,2}$ \\ 'Department of Clinical Sciences Lund, \\ Surgery, Lund University, Skane \\ University Hospital, Lund, Sweden; \\ ${ }^{2}$ Division of Surgery, Department of \\ Clinical Science, Intervention and \\ Technology, Karolinska Institutet, \\ Karolinska University Hospital, \\ Stockholm, Sweden; ${ }^{3}$ Division of \\ Radiology, Department of Clinical \\ Science, Intervention and Technology, \\ Karolinska Institutet, Karolinska \\ University Hospital, Stockholm, Sweden
}

Background and aim: Repeat hepatectomy is increasingly performed for the management of recurrent colorectal liver metastases (CRLM). The aim of this study was to evaluate longterm functional liver volume (FLV) after a second hepatic procedure and to measure survival outcome.

Methods: In this retrospective cohort study, patients treated for recurrent CRLM in the years 2005-2015 at two liver centers were included. Total FLV was calculated before the first procedure and before and after the second procedure. Overall survival was calculated.

Results: Eighty-two patients were identified. The median follow-up was 53 (40-71) months from the first procedure. The median interval between first and second procedure was 13 (8-22) months. The initial FLV was 1584 (1313-1927) $\mathrm{mL}$. The FLV was 1438 (1204-1896) $\mathrm{mL}$ after the first procedure and $1470(1172-1699) \mathrm{mL}$ after the second procedure $(P<0.001)$. After the second procedure, a total of ten patients $(12 \%)$ had a residual liver volume of less than $75 \%$ of the initial liver volume. The 5 -year overall survival was $37(26-54) \%$ after the second procedure.

Conclusion: Small changes in FLV were found after two hepatic procedures but with considerable inter-individual variation. Patients selected for a repeated hepatic procedure for recurrent CRLM had an acceptable survival.

Keywords: liver metastases, colorectal cancer, repeat hepatectomy, liver regeneration, postoperative outcomes

\section{Introduction}

Colorectal cancer is the third most common malignancy in the world ${ }^{1,2}$ and $15-20 \%$ of patients present with synchronous liver metastases at diagnosis. ${ }^{3-5}$ About $25-50 \%$ of all the patients will develop liver metastases (CRLM) during the course of the disease. ${ }^{6-8}$ Surgical resection or ablation of all tumors, when feasible, currently offers the only potential for cure.

Recurrence of metastases occurs in a majority of patients following hepatectomy either in the remnant liver and/or at other sites. ${ }^{9,10}$ In $20 \%$ of those, the remnant liver is the only site of recurrence. ${ }^{10}$ Repeat hepatic resections or ablations for recurrence are increasingly performed as a viable therapy for recurrent CRLM with acceptable overall survival. ${ }^{11-16}$

A minimum functional residual volume of $20-25 \%$ has been shown to be sufficient for a safe hepatic resection in case of a healthy liver parenchyma. ${ }^{17}$ Hepatocytes have a regenerative potential, and long-term functional liver volume
Correspondence: Christian Sturesso Division of Surgery, Department of

Clinical Science, Intervention, and Technology, Karolinska Institutet, I4I 86 Stockholm, Sweden

Tel +4 6725840657

Email Christian.sturesson@sll.se 
(FLV) after a major hepatectomy for CRLM has previously been shown to be around $80-90 \%$ of the initial liver volume. $^{7,18}$

Long-term volumetric liver regeneration after a repeated hepatectomy has been investigated to a lesser extent, with only one previous study including 21 patients. ${ }^{19}$ The aim of the present study was to retrospectively investigate volumetric liver regeneration and survival data after a repeated hepatic procedure (resection or ablation), hereinafter referred to as a second procedure, for liver recurrence of CRLM.

\section{Methods}

\section{Selection of patients}

All consecutive patients with CRLM who underwent a second procedure for the recurrence of CRLM at Skåne University Hospital, Lund, Sweden and Karolinska University Hospital, Stockholm between 2005 and 2015, were identified. Patients that had available imaging from computed tomography and/or magnetic resonance imaging were further selected. Patients were grouped according to whether they had major or minor hepatic procedures. A major liver procedure was defined as a resection of more than three Couinaud's segments. A minor hepatic procedure was defined as hepatic resection of less than three Couinaud's segments with or without additional radiofrequency ablation (RFA) or RFA alone. Synchronous disease was defined as when the liver metastases were diagnosed at the radiological workup of the primary cancer. The study protocol was approved by the Regional Ethical Review Board, Lund, Sweden (Dnr2016/ 989). Patient consent to review their medical records was not required by the review board due to the retrospective nature of the study. Patient data were analyzed after pseudonymization to ensure confidentiality and in compliance with the Declaration of Helsinki.

\section{Liver volume measurements}

Liver volumes were calculated using computed tomography or magnetic resonance imaging plane images. The liver contour on all image sections was manually traced and the area was automatically calculated. Each image section area was multiplied by the section thickness (typically $5 \mathrm{~mm}$ ) to obtain the liver volume. Metastasis volumes as well as ablation zones after RFA were measured in the same way and subtracted from the liver volume to give the FLV. The preoperative images of patients were selected on the basis of the most recent available images prior to first and second procedure. Postoperative images after the second procedure were obtained at least 1 month after procedure. Relative liver volumes were calculated by dividing the FLV after the first and second procedures to the initial FLV. For comparison, the total estimated liver volume (TELV) was calculated as TELV $=-794.41+1,267.28 \times$ body surface area (BSA), where BSA was calculated using Mosteller's formula: $\mathrm{BSA}=\sqrt{ }$ (height $[\mathrm{cm}] \times$ weight $[\mathrm{kg}] / 3,600) .{ }^{20}$ A liver tumor burden score (TBS) was calculated for each patient

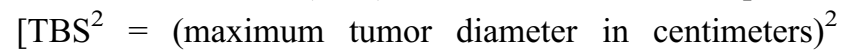
$\left.+(\text { number of liver lesions })^{2}\right] .^{21}$

\section{Statistics}

Summary statistics were presented as whole numbers and percentages for categorical variables, or as medians with IQRs, unless otherwise stated, for continuous variables. A Mann-Whitney U-test was used to compare continuous data, and Fischer's exact test was used for categorical data. A Friedman test was used when comparing three groups. Kaplan-Meier analysis was used to estimate survival. Overall survival was calculated using both procedures as the starting point. Pearson correlation analysis and linear regression were performed to assess the correlation between measured FLV and calculated TELV. A $P$-value less than 0.05 was considered statistically significant. Statistical analysis was performed using R (R Core Team (2016). R: A language and environment for statistical computing. R Foundation for Statistical Computing, Vienna, Austria. URL https://www.R-project.org/).

\section{Results}

A total of 99 patients with recurrent CRLM who underwent a second procedure were identified. Cross-sectional imaging prior to the first and second procedures and after the second procedure were available for 82 patients, which constituted the study cohort. The patient characteristics are shown in Table 1.

The median follow-up time was 53 (40-71) months from the first procedure and 38 (27-48) months from the second procedure. The time from first to second procedure was 13 (8-22) months. The time from initial imaging to first procedure was 2 (1-3) months. The time from the first procedure to the postoperative imaging was 11 (7-20) months and the time from second procedure to the postoperative imaging was 11 months (9-12) months. In Table 2, the size and number of metastases before each procedure are presented. 
Table I Characteristics of resected patients

\begin{tabular}{|c|c|c|}
\hline Number of patients & & 82 \\
\hline Age, years (IQR) & & $64(57-69)$ \\
\hline \multirow[t]{2}{*}{ Gender } & Male & $42(5 \mid \%)$ \\
\hline & Female & $40(49 \%)$ \\
\hline \multirow[t]{2}{*}{ Primary tumor site } & Colon & 48 (59\%) \\
\hline & Rectum & $32(39 \%)$ \\
\hline \multirow[t]{2}{*}{ Liver metastases timing } & Synchronous & $38(46 \%)$ \\
\hline & Metachronous & $44(54 \%)$ \\
\hline \multirow[t]{2}{*}{ Size of first hepatic procedure } & Major & $35(43 \%)$ \\
\hline & Minor & $47(57 \%)$ \\
\hline \multirow[t]{2}{*}{ Size of second hepatic procedure } & Major & 15 (I9\%) \\
\hline & Minor & $66(81 \%)$ \\
\hline \multirow[t]{3}{*}{ Resection order } & $\begin{array}{l}\text { Major to } \\
\text { minor }\end{array}$ & $35(43 \%)$ \\
\hline & $\begin{array}{l}\text { Minor to } \\
\text { major }\end{array}$ & $15(19 \%)$ \\
\hline & $\begin{array}{l}\text { Minor to } \\
\text { minor }\end{array}$ & 31 (38\%) \\
\hline $\begin{array}{l}\text { Perioperative chemotherapy (first } \\
\text { hepatic procedure) }\end{array}$ & & $67(82 \%)$ \\
\hline $\begin{array}{l}\text { Perioperative chemotherapy (second } \\
\text { hepatic procedure) }\end{array}$ & & 37 (49\%) \\
\hline
\end{tabular}

Table 2 Metastases specific characteristics of resected patients

\begin{tabular}{|l|l|l|l|}
\hline & $\begin{array}{l}\text { First hepatic } \\
\text { procedure }\end{array}$ & $\begin{array}{l}\text { Second hepatic } \\
\text { procedure }\end{array}$ & $\boldsymbol{P}^{\mathbf{a}}$ \\
\hline $\begin{array}{l}\text { Number of } \\
\text { metastases }\end{array}$ & $2(\mathrm{I}-4)$ & $\mathrm{I}(\mathrm{I}-2)$ & $<0.00 \mathrm{I}$ \\
$\begin{array}{l}\text { Maximum } \\
\text { tumor size } \\
(\mathrm{mm})\end{array}$ & $25(20-40)$ & $20(10-29)$ & $0.0 \mathrm{I}$ \\
Tumor score & $4(3-6)$ & $3(2-4)$ & $<0.00 \mathrm{I}$ \\
\hline
\end{tabular}

Notes: Values are median (IQR). ${ }^{\text {a }}$ Mann-Whitney $U$ test.

Median initial FLV was 1584 (1313-1927) mL. Median FLV after the first procedure was 1438 (1204-1896) $\mathrm{mL}$ and 1470 (1172-1699) $\mathrm{mL}$ after the second procedure $(P<0.001)$.

Relative liver volumes are shown in Figure 1, without difference between groups $(P=0.532)$. After the first procedure, nine patients had a FLV of less than $75 \%$ of the initial FLV, and ten patients had a FLV of less than $75 \%$ of the initial FLV after the second procedure.

Thirty-five patients had a major liver procedure as the first procedure (43\%) and $15(18 \%)$ as the second. Seven patients had only a RFA as the first procedure and eight as the second. The patients that had a major first procedure followed by a minor procedure showed significant liver volume reduction after the first procedure

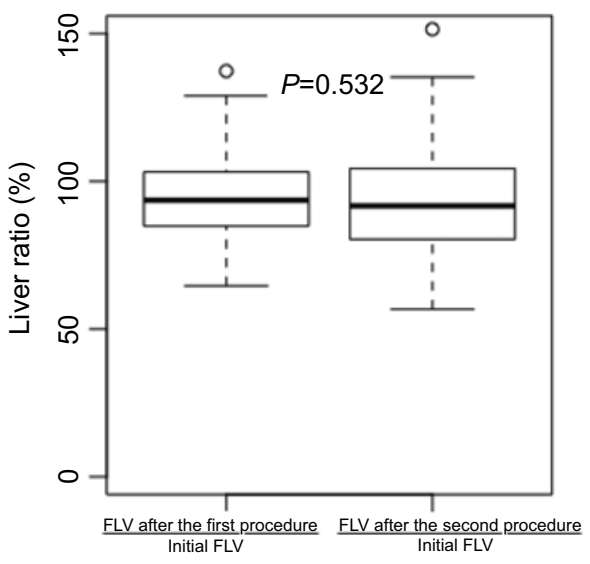

Figure I Liver volume ratios after the first and second procedures.Abbreviation: FLV, functional liver volume.

(1532 (1310-1692) $\mathrm{mL}$ vs $1271(1132-1438) \mathrm{mL}$, $P<0.001)$ but not after the second procedure $(P=0.242)$. The patients that had a minor first procedure followed by major second procedure did not show any significant reduction in liver volume after the first procedure $(P=0.391)$, but the reduction was significant after the second procedure (1796 (1252-2003) $\mathrm{mL}$ vs 1492 (1038-1840) $\mathrm{mL}, P=0.042$ ). Patients that had only minor procedures did not show any reduction in liver volume $(P=0.621$ and $P=0.792$, respectively $)$. A significant difference was found when comparing the relative liver volumes after the second procedure (FLR after the second procedure/initial FLV) between those that underwent one major procedure and those that only underwent minor procedures (87 (79-101) \% vs 98 (86-108) \%, $P=0.013$ ).

The administration of perioperative (neoadjuvant and/or adjuvant) oxaliplatin-based chemotherapy in relation to the procedures is shown in Table 1. Patients receiving perioperative chemotherapy $(n=74)$ did not show any significant difference in relative liver volumes after the second procedure (100 (94-108) \% vs $91(80-103) \%, P=0.200)$ as compared to patients not receiving any chemotherapy $(n=8)$.

The overall 5-year survival was 60 (47-70) \% after the first procedure and 37 (26-54) \% after the second procedure (Figure 2). No difference in complication (ClavienDindo classification $\geq 3$ ) frequency was found between the first procedure $(13(16 \%))$ and the second procedure (15 $(18 \%), P=0.846)$. No difference in survival was found between the groups undergoing only minor procedures versus the group undergoing major procedures $(P=0.947)$. A linear correlation was found between TELV and measured FLV before $(\mathrm{r}=0.57, P<0.001)$ and 


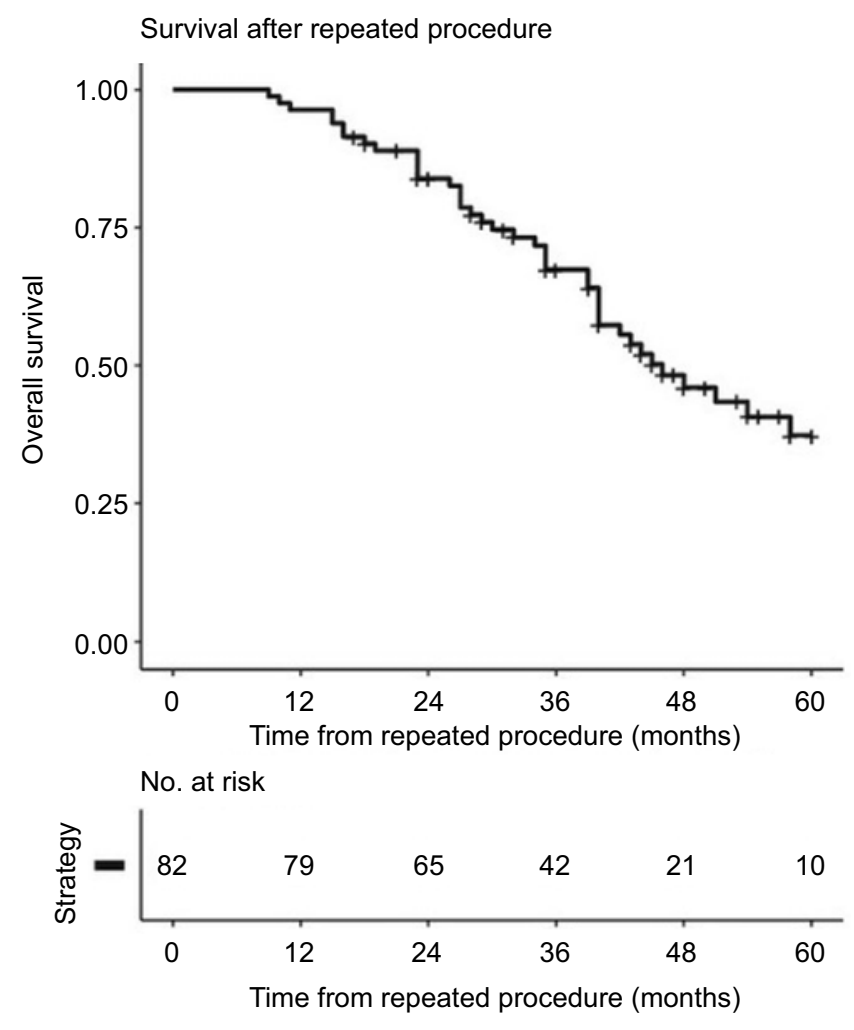

Figure 2 Overall survival after the second hepatic procedure.

after $(\mathrm{r}=0.68, P<0.001)$ the first procedure, as well as after the second procedure $(\mathrm{r}=0.55, P<0.001)$.

\section{Discussion}

Repeat hepatic procedures are increasingly performed, with acceptable results, as a viable therapy for recurrent CRLM. ${ }^{11-16}$ While it is known that hepatocytes have remarkable regenerative ability, it is not fully understood how repeated procedures affect the liver's ability to regenerate. This makes it unclear on which liver volume the estimation of a sufficient liver remnant should be based on when planning a second or even a third hepatic procedure. The aim of the present study was to evaluate volumetric liver regeneration and survival data for patients undergoing repeated procedures.

In the present study, the liver volume decreased minimally even after two hepatic procedures and almost reached the preoperative volume for most patients undergoing repeated procedures. This is in accordance with the results of the one previously published study on the subject, which included 21 patients. ${ }^{19}$ As could be anticipated, minor procedures did not result in any change in liver volume. $^{22}$ However, a significant reduction in FLV after was found after a major resection. This is well in line with previous studies assessing liver regeneration after one major resection. ${ }^{7,23,24}$

Perioperative chemotherapy was administered to $82 \%$ and $49 \%$ of the patients in relation to the first and second procedure, respectively. All patients were discussed at preoperative multidisciplinary team conferences. The reasons for the lower percentage of patients receiving chemotherapy in relation to the second procedure can only be speculated about. One plausible reason is that the oncologists question the value of chemotherapy as neoadjuvant/adjuvant therapy once recurrence of the liver metastases occurs. A similar reduction in utilization of perioperative chemotherapy has been reported previously, ${ }^{18}$ although others report no change in chemotherapy strategy in the case of liver recurrence. ${ }^{22}$ In the literature, there is a wide variation in the reported use of perioperative chemotherapy in relation to repeated hepatic procedures (44-90\%), ${ }^{12,19,25-27}$ reflecting that the value of perioperative chemotherapy in terms of outcome in the case of hepatic recurrence has not been fully investigated.

No difference in liver volume was found after two procedures between patients receiving chemotherapy $(n=74)$ as compared to those that did not receive chemotherapy (100 (95-108) \% vs $91(80-103) \%, P=0.200)$. However, only eight patients received no chemotherapy (Table 1). In a previous study, preoperative chemotherapy has been associated with a reduced long-term volumetric regeneration after liver resection, ${ }^{7}$ whereas other investigators have found no influence on regeneration of preoperative chemotherapy. ${ }^{18}$

At the first procedure, patients had a significantly higher number of metastases, larger metastases, and thus a higher TBS when compared to the second procedure. This is comparable to previous studies. ${ }^{25,26}$

A sufficient liver function is required to prevent postoperative liver failure. Liver volume and liver function are closely associated, and because liver volume is easier to calculate, most investigators determine preoperatively the volume of the future liver remnant to ensure a sufficient postoperative liver function. The future liver remnant is usually expressed as the volume of the future liver remnant divided by the total FLV. These volumes are readily calculated from cross-sectional imaging. An alternative to estimating the total liver volume is to use a formula based on the patient's BSA. ${ }^{20}$ There is some controversy about which method is superior in correctly estimating the risk for postoperative liver failure and for indicating the need for preoperative portal vein embolization. ${ }^{28,29}$ No studies exist on which volume to use when estimating the risk of liver failure in the case of re- or third-hepatectomy. For 
example, in the present study, $12 \%$ of patients presented a liver volume after the second procedure of less than $75 \%$ of the original liver volume. The estimated safe limit for excising additional liver tissue will, therefore, be quite different depending on whether the original liver volume or the liver volume after resections is used in the denominator when calculating the percentage of the future liver remnant. The alternative of using a TELV is then more appealing. However, although there was a significant linear correlation $(P<0.001)$ between TELV and measured total liver volumes before, after the first procedure and after the second procedure, the $r^{2}$ values were found to be $0.30-0.46$, indicating that the formula used accounts for only $30-46 \%$ of the variability in the measured total liver volume. Further studies are needed to address this issue.

Previous published studies have shown acceptable overall survival for patients that have undergone a second procedure after recurrent CRLM. ${ }^{11-15,25}$ In the present study, there was a median follow-up time of 53 (40-71) months from the first operation and $38(27-48)$ months from the second procedure. The overall 5-year survival was 37 (26-54) \% after the second procedure, as shown in Figure 2. A great variation in survival is found in the literature. A review article based on 47 studies found the overall 5-year survival after repeat hepatectomies to be $16-55 \%$, with few individual studies including more than 100 patients. ${ }^{30}$ Some studies have even reported 5-year overall survival of up to $75 \% .^{11,12,25}$ Lately it has been shown that ablation of liver metastases may offer comparable overall survival, but may be associated with reduced progressionfree survival. Ablation may offer shorter hospital length-ofstay and lower rate of complications. ${ }^{31,32}$ In the present study, seven patients underwent RFA as the first procedure and eight as the second procedure.

A shortcoming of the present study is that it is retrospective and subject to great selection bias, especially when analyzing survival outcome. In addition, no information was available about histological parenchymal damage that could potentially affect regeneration.

\section{Conclusion}

Little change in long-term FLV after a second hepatic procedure was found, but the inter-patient variation was high. Patients selected for a second procedure for recurrent CRLM had acceptable 5-year overall survival.

\section{Disclosure}

The authors report no conflicts of interest in this work.

\section{References}

1. Parkin DM, Bray F, Ferlay J, et al. Global cancer statistics, 2002. $C A$ Cancer J Clin. 2005;55:74-108. doi:10.3322/canjclin.55.2.74

2. Ferlay J, Soerjomataram I, Dikshit R, et al. Cancer incidence and mortality worldwide: sources, methods and major patterns in GLOBOCAN 2012. Int $J$ Cancer. 2015;136:E359-E386. doi:10.1002/ijc. 29210

3. Riihimäki M, Hemminki A, Sundquist J, et al. Patterns of metastasis in colon and rectal cancer. Sci Rep. 2016;6:29765.

4. Leporrier- J, Maurel J, Chiche L, et al. A population-based study of the incidence, management and prognosis of hepatic metastases from colorectal cancer. BJS. 2006;93:465-474. doi:10.1002/ bjs. 5284

5. Manfredi S, Lepage C, Hatem C, et al. Epidemiology and management of liver metastases from colorectal cancer. Ann Surg. 2006;244:254-259.

6. Mcmillan DC, Mcardle CS. Epidemiology of colorectal liver metastases. Surg Oncol. 2007;16:3-5. doi:10.1016/j.suronc.2007.04.008

7. Sturesson C, Nilsson J, Eriksson S, et al. Limiting factors for liver regeneration after a major hepatic resection for colorectal cancer metastases. HPB. 2013;15:646-652.

8. Steele G, Ravikumar TS, Ravikumar TS. Resection of hepatic metastases from colorectal cancer. Biologic perspective. Ann Surg. 1989;210:127-138.

9. Simmonds P, Primrose J, Colquitt J, Garden OJ, Poston GJ, Rees M. Surgical resection of hepatic metastases from colorectal cancer: a systematic review of published studies. $B r \quad J$ Cancer. 2006;94:982-999. doi:10.1038/sj.bjc.6603033

10. Ohlsson B, Stenram U, Tranberg K-G. Resection of colorectal liver metastases: 25-year experience. World J Surg. 1998;22:268-277. doi:10.1007/s002689900381

11. Andreou A, Brouquet A, Abdalla EK, Aloia TA, Curley SA, Vauthey J-N. Repeat hepatectomy for recurrent colorectal liver metastases is associated with a high survival rate. $H P B$. 2011;13:774-782. doi:10.1111/j.1477-2574.2011.00370.x

12. Pessaux P, Lermite E, Brehant O, Tuech -J-J, Lorimier G, Arnaud J-P. Repeat hepatectomy for recurrent colorectal liver metastases. J Surg Oncol. 2006;93:1-7. doi:10.1002/(ISSN)1096-9098

13. Chok KSH, Cheung TT, Chan ACY, et al. Survival outcome of re-resection for recurrent liver metastases of colorectal cancer: a retrospective study. ANZ J Surg. 2014;84:545-549. doi:10.1111/ ans. 12298

14. Morris E, Treasure T. If a picture is worth a thousand words, take a good look at the picture: survival after liver metastasectomy for colorectal cancer. 2017. Epub ahead of print. doi:10.1016/j. canep.2017.06.009

15. Antoniou A, Lovegrove RE, Tilney HS, et al. Meta-analysis of clinical outcome after first and second liver resection for colorectal metastases. Surgery. 2007;141:9-18. doi:10.1016/j.surg.2006.07.045

16. Luo LX, Yu ZY, Huang JW, et al. Selecting patients for a second hepatectomy for colorectal metastases: an systemic review and meta-analysis. Eur J Surg Oncol. 2014;40:1036-1048.

17. Kishi Y, Abdalla EK, Chun YS, et al. Three hundred and one consecutive extended right hepatectomies. Trans Meet Am Surg Assoc. 2009;127:171-179.

18. Simoneau E, Alanazi R, Alshenaifi J, et al. Neoadjuvant chemotherapy does not impair liver regeneration following hepatectomy or portal vein embolization for colorectal cancer liver metastases. J Surg Oncol. 2016;113:449-455

19. Tanaka K, Shimada H, Matsuo K, Ueda M, Endo I, Togo S. Regeneration after two-stage hepatectomy vs repeat resection for colorectal metastasis recurrence. Ann Gastroenterol Surg. 2007;11:1154-1161. doi:10.1007/s11605-007-0221-0

20. Vauthey JN, Abdalla EK, Doherty DA, et al. Body surface area and body weight predict total liver volume in western adults. Liver Transplant. 2002;8:233-240. doi:10.1053/jlts.2002.31747 
21. Sasaki K, Morioka D, Conci S, et al. The tumor burden score. Ann Surg. 2016;XX:1.

22. Paluszkiewicz R, Zieniewicz K, Kalinowski $P$, et al. Liver regeneration in 120 consecutive living-related liver donors. Transplant Proc. 2009;41:2981-2984.

23. Millet G, Truant SS, Leteurtre E, et al. Volumetric analysis of remnant liver regeneration after major hepatectomy in bevacizumab-treated patients. Ann Surg. 2012;256:755-762. doi:10.1097/SLA.0b013e31827381ca

24. Takeda D, Nitta H, Takahara T, et al. Effect of preoperative chemotherapy on postoperative liver regeneration following hepatic resection as estimated by liver volume. World J Surg Oncol. 2013;11:65. doi:10.1186/ 1477-7819-11-65

25. Muratore A, Polastri R, Bouzari H, Vergara V, Ferrero A, Capussotti L. Repeat hepatectomy for colorectal liver metastases: a worthwhile operation ? J Surg Oncol. 2001;76:127-132. doi:10.1002/(ISSN)1096-9098

26. Neal CP, Nana GR, Jones M, et al. Repeat hepatectomy is independently associated with favorable long-term outcome in patients with colorectal liver metastases. Cancer Med. 2017. Epub ahead of print. doi:10.1002/cam4.872
27. Wicherts DA, De Haas RJ, Salloum C, et al. Repeat hepatectomy for recurrent colorectal metastases. BJS. 2013;100:808-818.

28. Ribero D, Amisano M, Bertuzzo F, et al. Measured versus estimated total liver volume to preoperatively assess the adequacy of the future liver remnant. Ann Surg. 2013;258:801-807.

29. Martel G, Cieslak KP, Huang R, et al. Comparison of techniques for volumetric analysis of the future liver remnant: implications for major hepatic resections. HPB. 2015;17:1051-1057.

30. Lopez P, Marzano E, Piardi T, et al. Repeat hepatectomy for liver metastases from colorectal primary cancer: a review of the literature. Journal De Chirurgie Viscerale. 2012;149:107-113.

31. Dupré A, Jones RP, Diaz-Nieto R, Fenwick SW, Poston GJ, Malik HZ. Curative-intent treatment of recurrent colorectal liver metastases: a comparison between ablation and resection. Eur J Surg Oncol. 2017;43:1901-1907. doi:10.1016/j. ejso.2017.08.008

32. Hof J, Wertenbroek MWJLAE, Peeters PMJG, et al. Outcomes after resection and/or radiofrequency ablation for recurrence after treatment of colorectal liver metastases. BJS. 2016;103:1055-1062. doi:10.1002/bjs. 10087

\section{Publish your work in this journal}

Cancer Management and Research is an international, peer-reviewed open access journal focusing on cancer research and the optimal use of preventative and integrated treatment interventions to achieve improved outcomes, enhanced survival and quality of life for the cancer patient.
The manuscript management system is completely online and includes a very quick and fair peer-review system, which is all easy to use. Visit http://www.dovepress.com/testimonials.php to read real quotes from published authors. 